\title{
OCKHAM E A FILOSOFIA DA MENTE: aproximações ao externalismo na filosofia contemporânea
}

OCKHAM AND THE MENTAL PHILOSOPHY: aproaches to the externalism in the contemporary philosphy

$$
\text { AndersonD"Arc Ferreira * }
$$

RESUMO: No presente estudo pretendemos demonstrar alguns aspectos de meus estudos mais recentes de meu doutoramento. Nosso intuito é o de esboçar brevemente o sistema ockhamiano e, se possível, estabelecer possíveis aproximações desse autor medieval com o sistema do externalismo na Filosofia da Mente contemporânea. Essa linha de investigação onde se pretende desenvolver aproximações entre as temáticas medievas, especificamente de Guilherme de Ockham, e temáticas especificas das filosofias contemporâneas tem suas inspirações em estudos de Claude Panaccio e Alessandro Ghisalberthi. Nesse interim pretendemos demonstrar que as teorizações do "Príncipe dos Nominalistas" prefiguram uma estrutura muito semelhante às desenvolvidas na atual estrutura da linguagem mental. $O$ objetivo de nosso estudo é refletir acerca da possibilidade de existência, ou não, de uma Filosofia da Mente no medievo, especificamente em Guilherme de Ockham. Não focalizaremos o surgimento dessa problemática na Idade Média, mas deteremos nossas investigações no sistema lógico desenvolvido pelo Venerabilis Inceptor.

PALAVRAS-CHAVES: Lógica Medieval, Ockham, Filosofia da Mente, Externalismo.

\footnotetext{
* Doutorado em Filosofia pela Universidade Federal da Paraíba-UFPB (2010) com tese sobre filosofia da mente em Guilherme de Ockam. Professor Adjunto 1 da Universidade Federal da Paraíba. Coordenador do Programa de Pós-graduação em Filosofia-UFPB.
} 


\section{1 - Introdução}

Hodiernamente tem-se ouvido muito acerca da virada pragmático-lingüística em Filosofia. Essa "virada paradigmática" dentro da filosofia teria sido fruto de um movimento iniciado no início do século XX. Tal giro lingüístico promoveu toda uma necessidade de esclarecimento dos conceitos que fazem parte das linguagens ordinárias, por um lado, ou o esclarecimento dos significado dos enunciados das ciências, por outro. Contudo, um movimento parece-nos evidente, a saber: a necessidade de se esclarecer o uso da linguagem, seu alcance e suas implicações.

Esse movimento teve seu início com as obras de Frege sobre uma fundamentação lógica da matemática e amplia-se com o movimento iniciado por Wittgenstein, tanto o primeiro quanto o segundo. A abertura para as pesquisas da Filosofia Analítica, nesse sentido, estava criada. Tal movimento, contudo, não se conteve somente nas análises estritas acerca da lógica da linguagem. Dentre os movimentos que tomaram corpo o estudo dos processos mentais e seus pressupostos teóricos foram "despertos".

Com o ressurgir das questões relativas à reflexão filosófica que se ocupa dos atos mentais, e suas implicações, principalmente depois da influência das teorias do segundo Wittgenstein, as questões relativas à Filosofia da Mente voltaram à tona no ardoroso campo do debate filosófico. 
As reflexões acerca da mente, aspectos oriundos desde as teorias de Platão e Aristóteles, encontraram um solo fecundo no cristianismo, e em todas as religiões monoteístas, culminando na posição do dualismo cartesiano. Esse tema foi amplamente debatido por autores como Spinoza e Bérgson, dentre outros, chegando, no início do século XX, a teorias como as de Brentano, Willian James, Wittgenstein, Karl Popper, etc. Dessas discussões suscitadas pela Filosofia Analítica, e tendo tomado o debate como uma verdadeira questão filosófica, autores como Fodor, Putnam, Burge, Davidson, Kripke, Armostrong, Lewis, Searle, etc, tem desenvolvido estudos acerca dessa temática.

Nesse imbricado nicho de discussões encontra-se o solo acerca do qual situa-se nosso presente estudo, ou seja, temas relativos à Filosofia da Mente. Indubitavelmente, a obra de Franz Brentano constitui-se de um grande marco na Filosofia da Mente contemporânea. Em seus estudos Brentano ${ }^{1}$ desenvolve o conceito de "in-existência" intencional o qual aponta como sendo uma característica exclusiva dos fenômenos mentais. Nesse caminho para estabelecer as bases do conceito de "inexistência" intencional, ele começa por interpretar os estudos de Aristóteles mas utilizando-se da 'terminologia tomista' 2 para sua interpretação. Assim, esse crivo marca conceitos como os de existência 'natural' e 'intencional' de uma linguagem. Como em Brentano vemos uma grande utilização de concepções oriundas do período medieval, e em autores como Fodor e Putnam vários 
elementos do sistema Ockhamista fazem-se presentes, acreditamos que desenvolver uma aproximação entre o sistema ockhamista e a Filosofia da Mente Contemporânea seria de grande valia. Assim, pretendemos apresentar alguns pontos do sistema ockhamista e desenhar, se possível, aproximações desse sistema com o externalismo em Filosofia da Mente.

Nosso presente estudo, nesse ínterim, desenvolve uma linha tênue, de inspiração oriunda de Claude Panaccio, onde pretendemos mostrar algumas possíveis aproximações entre temáticas contemporâneas de Teorias da Filosofia da Mente com teorizações realizadas por Guilherme de Ockham em pleno século XIV, teorizações que prefiguravam uma estrutura extremamente atual de linguagem mental.

O objetivo de nosso estudo é refletir acerca da possibilidade de existência, ou não, de uma Filosofia da Mente no medievo, especificamente em Guilherme de Ockham. Não focalizaremos o surgimento dessa problemática na Idade Média, mas deteremos nossas investigações no sistema lógico desenvolvido pelo Venerabilis Inceptor. Acredito que tal exercício facilitará possíveis aproximações futuras entre o sistema lógico de Ockham e a temática da Filosofia da Mente hodierna ${ }^{3}$.

Para que o nosso percurso possa ter uma dinâmica maior iniciaremos nossas reflexões com uma breve visão do sistema ockhamiano. Em seguida trilharemos algumas possíveis aproximações entre o sistema lógico-lingüístico de Ockham e 
alguns aspectos pesquisados em Filosofia Analítica da Linguagem. Por fim, nosso maior interesse aqui, linhas aproximativas que nos possibilitariam desenvolver aproximações entre o sistema lógico-lingüístico teorizado pelo Venerabilis Inceptor e alguns aspectos relativos ao Externalismo em Filosofia da Mente.

\section{2 -O sistema Ockhamista}

Os séculos XIII e XIV foram muito fecundos para o período medieval. Vários movimentos foram desenvolvidos, tais como: a adoção dos métodos de Abelardo como intrínsecos à escolástica (lectio e disputatio); as condenações das 219 teses aristotélicas pelo Bispo Tempier em 1277; a disputa acerca do problema da pobreza evangélica (Papa versus Franciscanos); a disputa pelo poder temporal através da teoria dos dois gládios (Disputa de Ludovico da Baviera com João XXII); um enorme desenvolvimento das lógicas terministas (na época conhecida como Logica Modernorum).

O sistema de Ockham foi influenciado por dois dos maiores pensadores da Idade Média, Tomás de Aquino e Duns Scotus. Tomás tem como marca característica a realização da grande síntese entre a verdade revelada e a razão (fato esse que lhe concede o mérito de operacionalizar a síntese adotada pela escolástica), enquanto Scotus traz consigo a característica de 
prefigurar novas e decisivas idéias que irão focalizar os novos rumos do pensamento. Assim, se o século XIII foi o século das grandes sínteses, o século XIV será o século das grandes críticas.

A filosofia de Ockham inscreve-se, dessa forma, na crítica que os franciscanos dirigiam à síntese entre 0 cristianismo e o aristotelismo, crítica influenciada por Scotus e iniciada por Tomás de Aquino. O ponto de vista da nova proposta filosófica de Ockham trata-se de uma forma de empirismo epistemológico (notitia experimentalis) que o leva a produzir uma crítica radical a tudo o que era considerado desnecessário dentro do edifício filosófico ${ }^{4}$.

\section{1 - Linhas gerais do sistema ockhamiano}

Ockham admite que é possível conhecer intuitivamente o individual, sem recurso algum à abstração e a entidades ocultas, formas ou conceitos - todas são entidades às quais aplica seu princípio de economia do pensamento, princípio habitualmente conhecido como "navalha de Ockham". Essa postura leva-o a construir sua própria teoria do conhecimento (teoria expressa principalmente no seu importante prólogo ao Livro das Sentenças). Suas teorias levam-no a pensar uma teoria do conhecimento pautada no conhecimento intuitivo do singular, teoria denominada de notitia intellectualis. Assim, todo o conhecimento abstrativo que poder-se-ia acrescentar ao 
conhecimento intuitivo, notitia abstrativa, não supõe nenhuma nova operação do entendimento para a formação do conceito. Nesse sentido o nome abstrativo deriva do fato de que tal conhecimento abstrai, prescinde, da existência do indivíduo e, nele, o termo é considerado em si mesmo. Esse modelo leva à representação do objeto como um signo, mas não a uma abstração do objeto.

A lógica de Ockham trata dos termos enquanto formam parte de um sistema de signos lingüísticos. Ockham divide os signos em signo escrito (scriptus), podendo variar como vox, signo oral (prolatus) e signo mental (conceptus). O conceito é o signo mental (intentio) que remete às coisas existentes, somente é universal na medida em que representar uma pluralidade de indivíduos. Por outro lado os termos escritos ou falados, que são convenções, não podem ser naturalmente universais. Sua referência aos objetos individuais é seu significado. $\mathrm{O}$ significado, por sua vez, é explicado mediante a suposição (suppositio), ou seja, a capacidade do signo para ocupar o lugar de um objeto ou de uma coleção de objetos. A suposição, por sua vez, pode ser dividida em pessoal, simples e material. A suposição é pessoal se um termo ocupa o lugar de um indivíduo; é simples se ocupa o lugar de muitos sendo considerada uma intenção da mente; além do mais, podemos dizer que a suposição pode ser material, ou seja, quando existe uma referência a si mesmo.

Quando Ockham entra na disputa dos universais ele o 
faz valendo-se do recurso da suposição simples. Nesta perspectiva os nomes abstratos (intenções ou signos) podem ser absolutos ou conotativos. $\mathrm{O}$ nome ou termo absoluto tem como referente o objeto individual ou uma qualidade dele mesmo (a substância ou a qualidade), enquanto que o temo conotativo, cujos referentes seriam as categorias aristotélicas restantes não tem outro referente além do indivíduo, sendo que todo o resto apresenta-se como operação do entendimento. Os nomes, portanto, segundo a visão ockhamista, somente se referem ou a indivíduos ou a qualidades do indivíduo. É exatamente nessa redução da referência ao nome que está o caráter do seu nominalismo, título que foi levado a cabo por seus discípulos.

Com sua teoria do conhecimento intuitivo individual torna-se necessário, para o sistema ockhamista, recusar os clássicos argumentos escolásticos acerca da existência de Deus. Assim, ou Deus é conhecido intuitivamente, e não o é, ou somente é possível a fé em Deus. O mundo é visto como uma criação totalmente contingente de Deus, portanto, ele não pode ser pensado como um conjunto de relações necessárias. $\mathrm{O}$ mundo é um conjunto de coisas e dele somente conhecemos o que é possível através da via da notícia experimental. Nesse sentido são recusadas as noções de espaço e tempo, o movimento, etc., como algo distinto das coisas. Cabe à lógica a tarefa de averiguar o significado com que empregamos esses termos. Assim, o nominalismo se orienta cada vez mais através de uma ciência física que busca estar cada vez mais 
comprometida a indagar a forma de sucessão dos fenômenos, um ponto de vista que deixa de lado a tentativa de conhecer a realidade subjacente aos fenômenos. Esses elementos abrem caminho para a materialização de uma ciência física na qual se encaminharão, lentamente, todos os seguidores ockhamistas.

Sua valorização do concreto e do individual, além da perspectiva do conhecimento experimental, tem também aplicações no campo da teoria política: a separação entre fé e razão (por razões de um maior rigor em definir a ciência); distinção entre o poder civil e o poder religioso, segundo a teoria dos dois gládios; crítica à plenitude do poder teocrático; crítica à infalibilidade papal e concepção da Igreja como uma comunidade de fiéis e não como um domínio terreno.

\section{2 - O sistema Lógico de Ockham (1280 / 1347-50)}

Partindo do problema de que exista a possibilidade de se encontrar algo de comum que possa ser atribuído a Deus e às criaturas, Ockham mostra que somente um exame detalhado acerca dos universais poderá elucidar tal questão. Assim, sua preocupação será determinar o que são os universais e de que forma teríamos acesso a eles. A posição de Ockham a esse respeito não é citar ninguém, ou seja, tomar a posição de alguém, mas criar uma teoria própria que pudesse, através do apoio dos textos aristotélicos, solucionar esses problemas ${ }^{5}$. 
Contudo, seria impossível não dialogar com as teorias lógicas desenvolvidas até então.

No seu comentário ao Livro das Sentenças (Scriptum in Librum Primum Setentiarum) Ockham tenta apresentar uma solução a esse problema (questões 04 a 08). Assim, primeiramente ele examina a possibilidade da existência do universal fora da alma (questões 04 a 07) e chega à conclusão de que os universais somente podem existir ou se localizar dentro da alma humana (questão 8). Esse movimento acontece devido ao fato de que para Ockham tudo o que existe fora da alma é imediata e essencialmente singular. Assim, ele instaura, em seu sistema, a necessidade do "princípio de singularidade", ou seja, o indivíduo é a única realidade concreta. Nesse ínterim, nada existe fora da alma que não seja singular. Para Ockham " $a$ natureza universal não pode ser tomada como coisa (res)"6. Dessa forma considerado, o universal somente pode existir na alma, ou seja, o universal é um ser de razão, um conceito (conceptus). A operação realizada por Ockham muda o enfoque de tratar o problema dos universais. O problema é deslocado do estatuto ontológico (extra animam) para a direção da possibilidade de universalização dos conceitos na linguagem (estatuto lógico-semântico) ${ }^{7}$.

Nas investigações em que Ockham tenta determinar mais os aspectos relativos aos universais, ele examina três possíveis formas dos universais existirem: a teoria do fictum, a teoria da qualitas mentis e a teoria do ato mental (teoria a qual ele irá 
adotar). Assim para esta teoria o universal é identificado com o próprio ato de conhecer, aspecto que atrai a predileção de Ockham $^{8}$. De acordo com essa teoria do ato mental o ato da intelecção incide sobre uma realidade existente extra animam (aqui encontramos alguns traços de uma possível aproximação de Ockham frente ao externalismo). Nas palavras de Ockham temos:

(...) o conceito e todo o universal é uma qualidade existente subjetivamente na alma, que por sua natureza é como um sinal de uma coisa fora da alma, assim como a palavra é um sinal das coisas pela instituição voluntária ${ }^{9}$. E ainda, (...) há algumas qualidades existentes subjetivamente na mente, as quais por sua natureza lhes competem, tal como as características competem às palavras por instituiçẫo voluntária. ${ }^{10}$

Em textos posteriores, o Quodlibeta e a Summa Logicae, Ockham reafirma essa perspectiva da teoria do ato mental baseado no princípio de parcimônia, ou navalha de Ockham. Se por um lado ele resolve a perspectiva do universal extra anima, por outro lado fica em aberto a perspectiva do universal in anima. Para Ockham essa perspectiva somente poderá se tornar relevante quando situada dentro de uma teoria dos signos, ou seja, em uma perspectiva lingüística.

A função de um signo é significar. E isso ocorre em dois níveis: significação representativa (tudo o que é apreendido torna conhecida outra coisa - pressupõe um conhecimento prévio da coisa significada) e significação lingüística (aqui é acrescentada a capacidade suposicional do signo - agora o signo 
é caracterizado pela possibilidade de produzir uma intelecção primária, por sua função proposicional, estando orientado a ocupar o lugar da coisa significada em uma proposição - $e$ justamente por meio da suposição que um signo torna-se signo lingüístico e coincide com a noção de termo). Nessa linha onde se unem signos lingüísticos aos termos, os sinais podem ser divididos em dois grupos: signos lingüísticos naturais (termos mentais ou conceitos) e signos lingüísticos convencionais (termos escritos e falados). Os conceitos, destarte, exprimem diretamente a coisa significada. Já os signos mentais são produzidos através da interação do objeto e do intelecto. Os sinais convencionais são adquiridos mediante a convenção de uma instituição voluntária dos homens, culminando por estarem subordinados aos sinais naturais. Assim, as palavras escrita e falada foram inventadas pelo homem para designar coisas das quais os conceitos são sinais naturais ${ }^{11}$.

A seqüência montada a seguir estabelece a hierarquia dos signos em seu sistema. Uma coisa muito interessante aqui, é a inversão do triângulo semântico ${ }^{12}$ de Boécio. Ockham reestrutura a noção lingüística desenvolvida por Boécio, noção que chega até o sistema de Tomás de Aquino, e desenvolve outras relações entre palavras escritas, palavras orais e conceitos. O sistema ockhamiano ficaria $\operatorname{assim}^{13}$ : 
A esse respeito, os estudos de Bottin ${ }^{14}$ mostram que essas convenções de signos se referem-se a objetos externos. Mas vamos tratar disse no item 4 de nosso estudo. Agora, ficaremos com algumas aproximações do sistema ockhamista frente à Filosofia da Linguagem.

3 - Ockham e a Filosofia da Linguagem

Diante da 'pintura' que denominamos Filosofia Contemporânea, nosso autor parece fazer parte dos contextos dessa imagem. Durante muitos século Ockham ficou esquecido, suas teorias foram abandonadas e suas idéias deixadas de lado. Contudo, o grande historiador da lógica, C. Prantl ${ }^{15}$ retira os escritos de Ockham do reino do esquecimento dedicando algumas páginas de seu livro ao sistema lógico desenvolvido por nosso autor. 
Vários estudos foram implementados e as teorizações ockhamistas foram investigadas. Dentre esse emaranhado de estudos percebeu-se a importância de Ockham em vários campos da filosofia. Como aqui nos preocupamos com o sistema lógico do Venerabilis Inceptor, vale a pena ter em mente que sua obra, segundo a visão de Moody $^{16}$, baniu do aristotelismo medieval todos os resquícios de neoplatonismo que haviam sido introduzidos, na lógica, pelos estudos dos árabes. Nesse sentido o sistema de Ockham não pode ser visto como uma continuidade ou mesmo síntese dos sistemas lógicos do medievo, como alguns estudiosos chegaram a afirmar, mas deve ser visto como uma enorme crítica e busca de novas respostas.

Em sua concepção de lógica, Ockham entende a intelecção como algo vinculado ao signo, ou seja, na distância entre os signos mentais e as voces está a vertente que nos possibilita pensar sua filosofia da ciência como uma realidade lingüística interior ${ }^{17}$. Justamente nesse ponto, a concepção da intelecção como signo $^{18}$, está a ponte que liga as teorias de Ockham às análises desenvolvidas na filosofia da linguagem contemporânea. Sua estrutura, portanto, pode ser vista e entendida como sendo uma nova análise da estrutura do fenômeno cognoscitivo humano.

Se olharmos para o nominalismo de Ockham e o entendermos como uma análise do signo lingüístico, estaremos desenvolvendo uma linha que liga esse 'nominalismo' a uma 
'filosofia da linguagem'. Justamente no fato de analisar o signo lingüístico natural, ou conceito, está implícita uma visão do conhecimento como resultado de um sistema de signos lingüísticos naturais. Assim, a análise entre linguagem interior e linguagem natural que se faz presente no Venerabilis Inceptor é o tema de sua originalidade e contribuição ao campo das análises hodiernas acerca da linguagem.

No sistema okchamiano podemos falar em significação representativa e lingüística. Todas duas são geradoras de intelecção, ou seja, tem em si mesmas a capacidade de conduzirnos ao conhecimento de uma realidade que é distinta de nós. A significação representativa pressupõe um conhecimento prévio da coisa significada, ou seja, sua função é representar, é tornar presente ao intelecto algo que ele já havia conhecido. A significação lingüística, por sua vez, tem duas propriedades: ela não implica um conhecimento prévio e por isso engendra uma cognitio prima através do signo lingüístico; como o signo lingüístico tem a capacidade suposicional (ocupar o lugar da coisa significada em uma proposição) ele ocupa um lugar de destaque na estrutura lingüística. Assim, o signo lingüístico coincide com o termo podendo ser convencional (oral e escrito) ou natural. Dessa forma, o signo, entendido como signo lingüístico natural, apresenta-se como uma reação espontânea do nosso entendimento frente à realidade exterior. Uma forma de entendermos as relações entre o mundo interior e algumas formas de intelecção humana estão expressas nas figuras e 
relações que os signos podem representar, figuras e relações essas esquematizadas no quadro já exposto.

O que nos possibilita, segundo De Andrés ${ }^{19}$, a afirmar o caráter original de comparação da teoria ockhamista como uma filosofia da linguagem é sua teoria da proposição. Tal teoria confere aos signos (convencionais ou naturais) o caráter de propriedade proposicional, articulação que vincula radicalmente a propriedade dos signos lingüísticos a uma unidade lingüística primária, a proposição ou frase. Esse sistema apresenta-se como uma busca da justificação da validade do conhecimento "ao nivel 'molecular' da proposição"20.

Nesse breve excurso foi-nos permitido esboçar uma breve figura de como alguns aspectos desenvolvidos nas teorizações de Ockham aproximam-se a algumas das temáticas contemporâneas da filosofia da linguagem. Contudo, como nosso interesse é uma possível aproximação das teorias ockhamistas e o externalismo, cabe-nos, agora, deter-nos nos possíveis elementos que fariam a ligação entre o sistema lógico ockhamista e algumas temáticas relativas à Filosofia da Mente.

\section{4-Ockham e a Filosofia da Mente}

Antes de esclarecermos algumas possíveis comparações entre o sistema ockhamiano e o externalismo temos de entender o que é o externalismo. Comecemos, então, por esse viés.

Durante a primeira metade do século XX as teorizações 
do fundacionismo constituíram-se da vertente mais aceita acerca de algumas questões fundamentais de epistemologia, principalmente no que tange à forma de justificação de nossas crenças. Contudo, parece que essas idéias foram perdendo força e, hodiernamente, o fundacionismo é rejeitado por grande parte dos pesquisadores desse tema. Contudo, ainda permanece latente no âmbito filosófico a questão de se o aparato cognitivo humano e as formas pelas quais nós o utilizamos constituem-se de uma forma apta a produzir crenças precisas sobre o meioambiente que nos rodeia. O que mais fica evidenciado aqui é que devemos investigar acerca da possibilidade de que nossas crenças sejam errôneas e das condições para que possamos produzir conhecimento. Tal investigação assume, dessa forma, capital importância.

Se por um lado essas investigações oriundas do fundacionismo nos colocaram em um círculo vicioso do cartesianismo, por outro o externalismo parece-nos uma forma interessante de sair desse círculo sem cair em uma espécie de ceticismo. Uma das formas que os epistemólogos encontraram para dar conta do problema de quais condições são necessárias para que se produza o conhecimento foi o externalismo. Mas falar de externalismo requer entender que tipo de externalismo estamos tratando aqui e tentando ligar com as teorias de Ockham. Segundo Panaccio, o externalismo pode ver visto em pelo menos três formas distintas: o externalismo lingüístico, o externalismo do conteúdo mental e o externalismo epistêmico. 
O primeiro buscaria mostrar que o falante, no momento de sua enunciação depende de alguns elementos externos a ele, elementos que iriam além de suas estruturas internas. O segundo tipo defende a idéia de que o verdadeiro conteúdo que compõe as crenças de um agente não dependem unicamente de estados internos dessa agente, mas, também, de alguns fatores externos. A terceira forma de expressão de externalismo, dessa forma, postula que um agente acredita que o saber não depende exclusivamente de determinados estados internos do agente, mas, também, de alguns fatores externos.

Se por um lado pudermos entender que a pesquisa sobre o externalismo eclode a partir da segunda metade do século XX, parece-nos plausível averiguar a intuição de Panaccio que afirma uma interligação entre as teorias do Venerabilis Inceptor e as duas primeiras formas de externalismo acima determinadas. Vejamos, então, quais seriam os argumentos que nos possibilitariam afirmar esses elementos dentro da filosofia de Ockham.

Comecemos por averiguar uma passagem muito interessante do texto ockhamiano onde estão explicitados alguns aspectos relativos à teoria do ato mental:

Outra poderia ser a opinião, segundo a qual a paixão da alma é o próprio ato do intelecto. E porque essa opinião me parece ser a mais provável de todas as que estabelecem estarem subjetiva e realmente na alma essas paixões da alma, como verdadeiras qualidades dela, exporei primeiro o modo que me parece mais provável acerca dessa opinião (...). Digo, pois, que 
quem quer manter essa opinião pode supor que $o$ intelecto, apreendendo uma coisa singular, produz em si mesmo um conhecimento dessa coisa singular, apenas, conhecimento que se chama paixão da alma, capaz por sua natureza de representar a coisa singular. Portanto, assim como, por convenção, a palavra 'Sócrates' representa a coisa que significa de modo que, ao se ouvir a frase 'Sócrates corre' não se concebe que a palavra 'Sócrates', que se ouviu, corre, mas sim a corrida da própria coisa significada por ela, também, quem visse ou inteligisse ser afirmada alguma coisa dessa intelecção de alguma coisa singular não conceberia que a própria coisa a que o conhecimento se refere é assim. Logo, como a palavra convencional representa a própria coisa, também a intelecção, por sua natureza, sem convenção alguma, significa a coisa a que se refere. [grifo nosso] Mas, além dessa intelecção da coisa singular, o intelecto forma em si outras intelecções, que não pertencem mais a esta coisa que àquela. Assim como a palavra 'homem' não significa mais Sócrates que Platão e, portanto, sua suposição não é mais de um deles do que o outro, o mesmo se diria de tal intelecção que por ela não se inteligiria mais Sócrates do que Platão ou qualquer outro homem. Coisa igual se deveria dizer de qualquer outra intelecção, pela qual não se inteligisse mais este animal que outros, e assim por diante. Em suma, pois, as próprias intelecções da alma são chamadas paixões da alma e representam por sua natureza as próprias coisas exteriores ou outras coisas na alma, como as palavras representam as coisas por convenção. ${ }^{21}$ [grifos nossos]

Primeiramente comecemos por notar que Ockham considera as expressões conceito, afecções da alma, paixões da alma, intenções da alma e intelecto como sendo expressões sinônimas. Partindo desse esclarecimento inicial podemos ver no texto acima, dois pontos onde aponta-se um alinhamento entre as teorizações ockhamianas e as teses externalistas. Primeiramente ele remete a noção de intelecção da coisa 
referida. Em segundo lugar ele coloca as intelecções como sendo oriundas das coisas que estão fora da alma humana. Nesse sentido podemos notar que a teoria semântica do Venerabilis Inceptor nos mostra claramente que as palavras não significam conceitos, elas referem-se a coisas. Justamente aqui podemos ter uma forma de alinhamento entre o sistema de Ockham e o que afirma o externalismo lingüístico.

Em outra passagem notamos essa mesma referenciação das palavras como tendo seu referente em algo fora da alma humana, vejamos: “(...) o conceito e todo o universal é uma qualidade existente subjetivamente na alma, que por sua natureza é como um sinal de uma coisa fora da alma, assim como a palavra é um sinal das coisas pela instituição voluntária ${ }^{22}$ ". Assim, teremos a seguinte afirmação dentro de nosso sistema: "o ato da intelecção incide sobre uma realidade existente extra animan"23. Justamente aqui temos uma congruência entre o sistema que afirma uma primeira forma do externalismo, o lingüístico, com a segunda forma de externalismo, o do ato mental.

Para entendermos precisamente como um modelo implica em outro, dentro do sistema desenvolvido pelo Venerabilis Inceptor, temos de entender a forma de dependência semântica que nosso autor postula. Realmente podemos falar em uma forma de dependência semântica dentro desse sistema. Contudo devemos visualizar que tal dependência semântica acontece das palavras em relação aos conceitos. Essa relação de 
subordinação é expressa na teoria da subordinação. Entrementes, podemos notar que a formulação de uma espécie de linguagem mental em Ockham iniciam elementos que também nos garantem e atestam a união das duas formas de externalismo.

Vejamos, primeiramente, a confirmação das relações semânticas dentro da teoria da subordinação ockhamiana. O texto a seguir é retirado da mais acabada obra lógica de nosso autor, a saber, a Suma Lógica. Nas palavras de nosso autor temos: "O ponto é mais propriamente que as palavras faladas estão impostas para significar as coisas autênticas que são significadas por conceitos da mente, de modo que um conceito primaria e naturalmente signifique algo e uma palavra falada signifique a coisa mesma secundariamente" 24 . Essa relação de subordinação, contudo, parece ficar mais clara a partir da seguinte passagem:

Primeiramente, cumpre saber que se chama intenção da alma algo na alma destinado a significar algo diverso. Assim, como foi dito antes, do modo em que o [termo] escrito é signo secundário com respeito às palavras faladas, porque entre todos os signos convencionalmente instituídos, as palavras faladas têm o primado, assim as palavras faladas são signos secundários daquilo de que as intenções da alma são signos primários. E, por isso,diz Aristóteles que as palavras faladas são 'marcas daquelas coisas que são paixões da alma '. Aquilo, porém, existente na alma, que é o signo da coisa, a partir do qual a proposição mental se compõem - ao modo em que a proposição vocal se compõe de palavras faladas -, e às vezes chama-se intenção da alma, às vezes similitude da coisa, e Boécio, no Comentário ao Perihermenéias, chama intelecção. Assim, ele pretende que a proposição 
mental seja composta de intelecções, não certamente de intelecções que são realmente da alma intelectiva, mas de intelecções que são certos signos da alma, significando outras [coisas] e dos quais a proposição mental é composta. Assim, quando quer que alguém profira uma proposição falada, antes forma interiormente uma proposição mental, que não é de idioma algum, tanto que muitos freqüentemente formam interiormente proposições que, em razão de defeito do idioma, não sabem expressar. As partes dessas proposições mentais chamam-se conceitos, intenções, similitudes e intelecções ${ }^{25}$. [grifos nossos]

No sistema ockhamiano notamos que existe uma realidade, a linguagem mental. Essa linguagem mental é uma forma de realidade psíquica onde falar e compreender seriam operações que corresponderiam, na mente humana, à associação de sinais sonoros a formas de representações mentais realmente existentes em cada um. A linguagem mental em Ockham é uma teoria acerca da mente humana. Debaixo dessa teoria podemos notar a idéia da subordinação, ou seja, uma estrutura onde poder-se-ia exprimir, através de signos vocais, termos mentais. Nesse sentido a linguagem mental teria a função ou capacidade puramente referencial. Essa estrutura coloca nossos atos mentais em estreita conexão com a linguagem, não com uma forma de psicologismo. Para nosso lógico medieval temos que o ato intelectivo, entendido como um signo de uma coisa singular, é algo de real, mesmo que isso se remeta à uma pura intenção da mente. Essa característica liga alguns traços da linguagem mental de Ockham frente ao segundo tipo de externalismo. Por mais que ele afirme a necessidade de um ato mental ele sempre 
postula a necessidade de algo externo ao agente para dar o início aos procedimentos que envolvem os atos mentais e, por conseguinte, à linguagem mental. Nesse sentido Ockham chega a postular que existem representações mentais que se referem necessariamente a coisas externas. Contudo, essas representações acontecem no mesmo nível do conceito, não ao nível das imagens. Essas idéias, expressas no conjunto e interface de suas teorias da suposição e da conotação, mostram uma enorme similaridade com as idéias de Putnam.

5 - Considerações Finais

Como foi salientado até aqui, é possível vislumbrar algumas das idéias do Venerabilis Inceptor em complexo diálogo com formulações contemporâneas tanto na filosofia analítica quanto da filosofia da mente. Teorias como a da referenciação direta e externalismo, dentre outras, aproximamse muito de algumas idéias defendidas por nosso lógico medieval.

Contudo, esse trabalho apresenta-se somente como o início de um estudo. Sabemos que muito mais pode ser evidenciado e desenvolvido no que tange a aproximações entre Ockham e alguns sistemas filosóficos contemporâneos. Infelizmente tais aproximações não puderam ser mais detalhadas nesse presente trabalho.

Nosso objetivo aqui foi apontar para possíveis 
alinhamentos de Ockham frente ao externalismo. Não pretendemos, contudo, estabelecer a pedra fundamental de um novo edifício, mas tão somente pensar em novos horizontes dialogais para questões antigas. Nesse ínterim vimos como as questões da Filosofia da Mente voltam à tona hodiernamente. Voltamos nosso olhar para a 'espiada' que alguns componentes da filosofia analítica fizeram para as teorizações medievais. Nesse caminho ficou claro que existem vários aspectos no lógico medieval que se caracterizam como grandes aproximações das teorias produzidas hodiernamente. Contudo, quando entramos no alinhamento básico do externalismo frente às idéias de Ockham é que as coincidências se tornaram muito interessantes. Com certeza as aproximações que foram desenvolvidas aqui ainda são incipientes e ainda dar-se-ão, ao longo de outros trabalhos. Através de posteriores estudos, pretendemos demonstrar, de forma mais detalhada e complexa, de que forma e em que pontos específicos as teorias do nosso mestre franciscano tornam-se efetivas interfaces dialogais com o externalismo em filosofia da mente.

O externalismo alinha-se muito com várias noções do sistema lógico de Guilherme de Ockham. Demos início a uma reflexão que aponta para isso. O caminho foi aberto, o horizonte ainda se apresenta como uma senda a se explorar.

Referências Bibliográficas 
BOTTIN, Francesco. Filosofia Medievale della mente. Padova: Il Poligrafo, 2005.

LEITE JUNIOR, Pedro. O problema dos Universais: a perspectiva de Boécio, Abelardo e Ockham. Porto Alegre: EDIPUCRS, 2001, p.112.

PANACCIO, Claude. Semantics and Mental Language. In.: SAPADE, Paul Vincent (org.) The Cambridge Companion to OCKHAM. New York: Cambridge University Press, 1999.

MOODY, Ernest A. The Logic of W. of Ockham. New York: Russel \& Russel, 1965, p.52-53.

DE ANDRES, Teodoro. El nominalismo de Guillermo de Ockham como Filosofia Del Linguaje. Madrid: Gredos.

\section{Notas}

1 A esse respeito Cf. o estudo de Brentano denominado 'A psicologia do ponto de vista empírico'.

2 Cf. BOtTIN, Francesco. Filosofia Medievale della mente. Padova: Il Poligrafo, 2005. Nesse estudo, p. 13, Bottin fornece vários apontamentos que estabelecem as interfaces entre o sistema desenvolvido por Brentano e sua ligação com as teorias medievais acerca da Filosofia da Mente.

3 Algumas aproximações feitas recentemente e que demonstram a viabilidade dessas aproximações podem ser encontradas na Revista Veritas. A esse respeito conferir: REVISTA VERITAS. Porto Alegre, v.45, n.3, Set. 2000. p.313-504. Trimestral. ISSN 0042-3955.

4 Esse empirismo epistemológico deve-se ao fato de que para Ockham o intelecto somente pode ter acesso ao indivíduo. Esse acesso ocorre do encontro do intelecto humano com um objeto do mundo sensível. Para que fosse concretizado esse movimento era necessária uma ferramenta que eliminasse os exageros produzidos pelos sistemas lógicos que lhe antecederam. Esse princípio conhecido como 'princípio da economia'.

5 Cf. BOTTIN, Francesco. Filosofia medievale della mente. 2005, p.134 e seguintes.

6 LEITE JUNIOR, Pedro. O problema dos Universais: a perspectiva de Boécio, Abelardo e Ockham. Porto Alegre: EDIPUCRS, 2001, p.112.

7 Ibdi, p.139. 
8 "a inteleç̧ão, por sua natureza, sem convenção alguma, significa a coisa a que se refere". Trad. de Pedro Leite, op. cit, p. 144. Essa passagem pertence ao texto de Ockham na Expositito in Librum Perihermenias Aristotelis, 351, 4-352, 32 que foi editada pelo Instituto São Boa Ventura.

9 “(...) conceptus et quodlibet universale est aliqua qualitas exsistens subiective in mente, quae ex natura sua ita est signum rei extra sicut ox est signum rei ad placitum instituentis." L. Sent., VIII, 289, 13-15.

10 “(...) ita sunt quaedam qualitates exsistentes in mente subiective, quibus ex natura competunt tália qualia competunt vocibus per voluntariam institutionem." L. Sent., VIII, 290, 1-3.

11 A esse respeito cf. Pedro, op. cit., p. 150-154.

12 BOTTIN, op. cit., p. 148, sustenta que existem diferentes concepções a esse respeito, dentre elas a de Panaccio.

13 Essa figura é um desenho esquemático retirado de BOTTIN, op. cit., p.149. A mesma figura vem expressa em um estudo de Panaccio, p55. Nesse ínterim Cf. PANACCIO, Claude. Semantics and Mental Language. In.: SAPADE, Paul Vincent (org.) The Cambridge Companion to OCKHAM. New York: Cambridge University Press, 1999, p.53-75.

14 BOTTIN, p.149. Aqui Bottin mostra o quadro do triângulo semântico descrito acima. Contudo, na página 143, o autor descreve como devemos entender essa exterioridade dos signos em Ockham, conforme a citação que foi feita.

15 Cf.: C. PRANTL: Geschichte der Logik in Abendlande, t. III, p. 327-420 In: DE ANDRÉS, Teodoro. El nominalismo de Guillermo de Ockham como Filosofia Del Linguaje. Madrid: Gredos, p.10.

16 MOODY, Ernest A. The Logic of W. of Ockham. New York: Russel \& Russel, 1965, p.52-53.

17 Cf. DE ANDRÉS, op. cit., p.18-23.

18 Essa foi a tese apresentada por DE ANDRÉS em seu livro supracitado. Em todo o seu estudo DE ANDRÉS apresenta várias formas nas quais poderíamos desenvolver uma aproximação entre as teorias de Ockham e a Filosofia da Linguagem Contemporânea.

19 DE ANDRÉS, op. cit., p.284. 
20 DE ANDRÉS, op. cit., p.284.

21 Cf. OCKHAM, Guilherme. Expositio in librum Perihermenias Aristotelis, 351, 4-352, 32. In: Opera Philosophica II. Ed. Gambatese et S. Brown. Cura Instituti Franciscani, Universitatis S. Bonaventurae, ST. Bonaventure: N.Y. 1978.

22 Cf. OCKHAM, Guilherme. Scriptum in Librum Primum Sententiarum. Ordinatio (Distintiones II-III). VIII, 289, 13-15. In.: Opera Theologica II. Ed. S. Brown, adlaborante G. Gál. Cura Instituti Franciscani, Universitatis S. Bonaventure, St. Bonaventure: N.Y. 1970.

23 Cf. Pedro, op. cit., p. 145.

24 OCKHAM, Summa logicae I, 1. In: Opera Philosophica I. Ed. Ph. Boehner, G. Gál. E S. Brown. Cura Instituti Franciscani, Universitatis S. Bonaventurae. St. Bonaventurae: N. Y. 1974.

25 OCKHAM, Summa logicae I, 12, 41, 8-42, 28. 